\title{
PERSPECTIVES OF COMMUNITY PARTNER ORGANIZATIONS IN THE DEVELOPMENT OF ETHICAL SERVICE-LEARNING GUIDELINES
}

\author{
Meghan Doran, Colin Rhinesmith, and Sarah Arena
}

\section{Abstract}

This research brings the voices of community partner organizations into the discussion of ethical obligations of university and student partners in community-based learning. We used a framework for servicelearning ethics developed by Wendler (2012), which brings The Belmont Report (1979) on research ethics together with decolonizing, feminist, and participatory action research frameworks, to guide our interviews with staff members of community organizations about their experiences and beliefs about the ethical obligations of faculty and students partnering with service-learning courses. We found that the community organization perspective deepened our understanding of the categories elaborated in the Wendler framework (i.e., respect, reflexivity, beneficence, and justice) and situated them in relationship to one another as context, process, and outcome. Based on these findings, we introduce a relational approach to service-learning ethics that centers social justice, and we offer seven key principles to reflect the perspectives of community partners in our ethical practice.

Within the field of service-learning/community engagement (SL/CE), a growing body of work has focused on the ethical dimensions of pedagogies that involve engagement with communities outside of the university walls. This line of inquiry has brought together best practices in SL/CE more broadly with the preexisting structural frameworks of research ethics to ask the following question: What are the ethical obligations of students and faculty members working with community organizations? Service-learning involves a layered set of relationships and power dynamics between faculty, students, university administrators, community partner organizations, and the community members those partners serve (Bringle et al., 2009). Each of these sets of actors has their own perspectives, needs, and goals when participating in a service-learning experience. Furthermore, such a partnership is embedded in a complex web of power dynamics, including but not limited to those internal to the university (between students, faculty, and administrators), those internal to community organizations (including between the organization and the community it serves), and the historical relationship between the university and the communities in which it resides. All of these relationships are further embedded in broader social systems of oppression, in particular those related to race, class, and place. Given these dynamics, service-learning 
practitioners seeking to center social justice in community practice must consider not only their own perspectives on ethical practice but also what their partners in the process consider to be ethical.

While the service-learning scholarship has considered both community partner perspectives on partnership formation and the university, community partner perceptions of ethical service-learning remain largely unexplored. To address this gap in the literature, and also to understand the perspective of the community organizations we as a university have partnered with, we proposed the following research question: What are the ethical obligations of students and faculty members working with communities from the perspective of community partners? As a university staff member, a faculty member, and a graduate student, respectively, we each have experience with service-learning and are familiar with the literature on best practices and ethics. Despite having each worked with community partner organizations, either currently or in the past, we were also aware going into this study of our own limited understanding of how community organizations might perceive our ethical obligations as service-learning practitioners inside a university environment. In response, we used Wendler's (2012) ethical engagement framework as a critical theoretical framework, to guide our interviews with community partner organizations about their perspectives on the ethics of service-learning in community-university partnerships.

In this article, we present findings from interviews with community-based organizations in New England about their perspectives on the ethical obligations of their university and student partners in service-learning projects. The research involved interviews with staff members in 12 separate community-based organizations that are currently or have recently (within the last 24 months) partnered with a service-learning course at our institution. We investigated their beliefs about the ethical obligations of faculty and students partnering with them and their experiences in these types of partnerships. We used a framework for service-learning ethics developed by Wendler (2012), which brings The Belmont Report (National Commission for the Protection of Human Subjects of Biomedical and Behavioral Research, 1979) on research ethics together with decolonizing, feminist, and participatory action research frameworks, to consider how community partner perspectives compare to scholarly approaches to ethics in SL/CE. Our findings show an expressed desire of our community partners to have more ownership over decision-making processes as well as the importance of strong relationships grounded in open communication and consent to guide both the process and outcomes of successful service-learning partnerships. Based on these findings we introduce a relational approach to service-learning ethics that centers social justice, and we offer seven key principles to reflect the perspectives of community partners in our ethical practice. We conclude by discussing how the contributions from our study can help to promote socially just relationships in community-based learning opportunities.

\section{Literature Review}

\section{Community Partner Organization Perspectives}

The principles of critical service-learning pedagogy (Mitchell, 2008) are seen in a growing body of research that includes community perspectives through interviews, focus groups, and collaboration in the classroom, on course 
design, and with research (Holmes, 2009). Incorporating community perspectives makes space for partners to share their own needs, motivations, perceptions, and concerns in service-learning partnerships (Worrall, 2007). Critical service-learning encourages communities to initiate, participate in, lead, or set the terms for servicelearning initiatives, thereby flipping narratives of who serves and who is served (Bucher, 2012; Padmanabha, 2018; Reed \& Butler, 2015). Furthermore, it challenges students to "engage with community members in a manner that acknowledges their position as experts" (Garoutte, 2018, p. 152). These reconceptualizations of service can strengthen outcomes, improve student learning, create more equitable partnerships, and potentially decolonize existing power structures.

To form and maintain more effective service-learning partnerships and projects, best practices recommended by community partner organizations include prioritizing building partnerships and respecting the organization's mission, resources, and human dimensions, as well as regarding "process as important" (Tinkler et al., 2014, p. 137). Based on interviews and discussion groups with nonprofit staff, Stoecker and Tryon (2009) suggest a set of community standards around five themes for higher education faculty and staff to follow: communication, developing positive relationships, providing an infrastructure for service-learning, managing service-learners, and promoting diversity in service-learning. The authors recommended that partnerships focus on managing expectations and including accountability mechanisms as well as preparing students for service through diversifying student recruitment and cultural competence education.

In addition to asking questions on how to form service-learning partnerships, other scholars underscore the importance of paying attention to who starts partnerships and who makes choices about goals that may also lead to new ways of generating knowledge and minimizing power dynamics (Glover \& Silka, 2013). For example, Racin and Gordon (2018) created a memorandum of understanding (MOU) for community partners at the beginning of partnerships to identify needs and work through potential issues. Areas of discussion include resource and knowledge sharing; communication and relationship building; and questions around data generation, usage, and storage during and after the project. Creating space to discuss and document service-learning partnerships at the onset of projects aims to give community organizations and constituents structures and outcomes that will support their aims in a more thoughtful manner. These and other insights from the literature highlight some of the ethical concerns that have been raised about service-learning, particularly in the processes and outcomes related to community-university partnerships.

\section{Ethical Service-Learning and Social Justice}

While the codification of research ethics after World War II has led to increased oversight and concern for research subjects in scientific and medical research (Paul, 2018), similar discussions of ethics in service-learning have been largely absent. Exemplified by The Belmont Report (National Commission for the Protection of Human Subjects of Biomedical and Behavioral Research, 1979), researchers and governing bodies starting in the 1940s and 1950s became increasingly concerned with establishing codes of ethics that protect human subjects through requiring informed consent, weighing risks and benefits, considering who bears the burden of serving in medical research trials, and approving research through review boards. These practices undergird the ethical principles of 
human subjects research and shape how research is conducted and even how researchers conceive of their own practice. Yet while this framework exists for mitigating harms to human subjects, similar principles have not been adopted or institutionalized in teaching and service-learning contexts. Discussions in service-learning have predominantly focused on student learning, including increasing student awareness of community issues and civic responsibility (Blizek, 2013; O’Brien et al., 2017). Few ethical protections and guidelines have been established for interactions involving community members and community organizations.

The language and principles of the institutional review board (IRB) have been used by some scholars to consider the ethical issues in service-learning projects. For example, as Rich (2003) asked, "What are our ethical obligations in the service-learning arena when we are not conducting formal research?” (p. 112). Drawing on ethical issues in academic research, Rich argued that a number of ethical issues should be considered in servicelearning, including issues of consent, confidentiality and privacy, and harms to and exploitation of constituents, while ethical concerns might arise for students around lack of supervision and training, time requirements, or exposure to confidential or sensitive information. Scholars have also raised concerns about the limitations of the IRB for community-based research and service-learning. For example, Gorski et al. (2015) recommended moving beyond the culture of compliance created by the IRB to a culture of concern through establishing an engagement review board. Others have found the IRB model to be inadequate in ethically mediating the multiple actors with conflicting relationships and ethical responsibilities that exist within a university-community partnership (Danley \& Christiansen, 2019). In their review of the literature on the ethics of community-based participatory research, Mikesell et al. (2013) found that The Belmont Report's principles proved to be an insufficient framework to protect communities or handle changing needs and ethically ambiguous situations that may arise during collaborations with community partners.

Rather than relying on the principles of institutional review for research ethics, scholars have begun to explore the power relationships in community-university service-learning partnerships in order to generate new frameworks and recommendations for ethics in working with both students and community constituents (Bringle \& Hatcher, 2002) - all of which connect to broader social justice goals. Chapdelaine et al. (2005), for example, outlined the ethical responsibilities of students, faculty, and administration to address the following principles: beneficence, nonmaleficence, justice/fairness/equity, fidelity/responsibility, autonomy and respect for people's rights, and integrity. Wendler (2012) offered a conceptual framework rooted in human subjects protection and The Belmont Report (National Commission for the Protection of Human Subjects of Biomedical and Behavioral Research, 1979) and also informed by decolonizing, feminist, and participatory action research perspectives. The framework outlines four principles:

1. Respect for persons ensures participation that is respectful, asset based, and occurs without coercion and with clear understanding and consent from all stakeholders.

2. Beneficence situates the project as being of benefit to the university and community and also considers benefits, risks, and a range of harms (eotional harms, human resource harms, service harms, program harms, privacy and confidentiality harms). 
3. Justice calls attention to power through the micro-dynamics of partnership as well as macro-social dynamics.

4. Reflexivity asks students and faculty to understand their situatedness.

Wendler recommends that these principles not be institutionalized but instead be flexible and context specific. Wendler's framework offers an opportunity to consider how service-learning as a field and in individual projects can more explicitly embody ethical research principles within the context of partnership formation, project implementation, and community interactions. We also believe this approach allows us to interrogate our own assumptions about our ethical responsibilities as university partners in service-learning projects as well as our efforts to promote social justice goals.

We define "social justice" in this article specifically in the context of community practice. Drawing upon Reisch et al.'s (2012) scholarship in the field of social work, we assume that "working with communities to promote social justice involves the transformation of institutions, structures, systems, and relationships to be more inclusive, democratic, and redistributive” (p. 86). This definition of social justice in community contexts stands in contrast with ethics, which we consider more in relation to ethical standards or codes of ethics that inform professional practice, such as within journalism or social work. Reisch et al.'s centering of social justice within community practice connects directly to our engagement with Wendler's ethical service-learning framework in its focus on asking practitioners to "critically examine the theories and practice models they are using in their work with communities and recognize how differences in social locations, multiple and conflicting identities, cultural standpoints, and power affect relationships within and across communities and between communities and practitioners" (p. 86). Here we are not attempting to use the two concepts synonymously. Rather, we assume ethics - and, more concretely, ethical service-learning - to be situated within and in support of Reisch et al.'s above definition of social justice in community practice.

Wendler's (2012) framework has been applied and augmented with Indigenous practices and methodologies to refocus service-learning students' efforts from students' strengths and rights (what students can do) to community strengths and rights (what kind of interventions communities want) (Padmanabha, 2018). By rooting service-learning in the traditions and agency of the community, Padmanabha's (2018) framework challenges service-learning students and educators to learn from the dissonance they feel acting as listeners without the "service" component they expect of service-learning. Wendler and Padmanabha help illustrate that working toward more ethical service-learning includes adapting and integrating definitions and modes of service defined by the communities being served. Applying these principles to on-the-ground partnerships allowed us to examine issues of power, privilege, and marginalization in service-learning and how perspectives from community partners could be factored into ethical considerations in community-university partnerships. 


\section{Research Design}

\section{Research Process}

To address our research question - What are the ethical obligations of students and faculty members working with communities from the perspective of community partner organizations?-we interviewed 12 participants between November 2018 and February 2019 from the organizations listed in Table 1, which were anonymized to protect the privacy of our participants. The research question was conceived of by the first two authors, and the third author was brought in not long after to assist with the review of the literature. Work was shared relatively equally between the three authors through the research process of participant recruitment, data collection, and data analysis, all of which are discussed below.

Power imbalances existed between the authors through different relationships to the university as experienced by full-time faculty and staff as opposed to a stipended graduate student, including time commitments and compensation. As a graduate student with a limited time commitment to the university, the third author was not involved in the inception of the original study design and was no longer associated with the university at the time of publication. Some of the downstream effects of this limited time commitment for the third author included an uneven contribution to the study design, inability to ensure follow-up on interviewee suggestions, and uneven ownership over implementing findings at the university level. The first and second authors included the third author in all discussions after she joined the project, and all authors shared time and work commitments during the analysis and writing stages of the project. We also discussed questions about compensation for research conducted outside the contracted period of the third author's stipend, as well as the time commitment each researcher could be expected to contribute. The investigators attempted to mitigate some compensation imbalances through locating additional funding for the third author for research conducted during university breaks.

The first author is a university staff member whose formal role includes building and maintaining relationships with the partners involved in this research study, but this role does not require the production of original research. For this reason, she has perhaps the least protections in terms of intellectual freedoms in the research. She initiated this research in part to inform her own work and subsequently had to maintain a balance between her relational role with partners and conducting this research. She thus removed herself from the interview process, which meant that labor fell on her co-authors, but she balanced that labor with other contributions, particularly in compiling information about the university's organizational partners. Furthermore, it is likely that the third author's direct knowledge and relationship with many (though not all) of the community partner organizations interviewed for this study played a role in her analysis. She brought her own insights to the analysis based on these experiences but was also careful to check these insights against what the other two authors, who did not have such direct relationships, were seeing in the data.

The second author of this article is a white male university professor with arguably the most unearned power and privilege among the three authors due to his social location and position at the university. During the study, 
the second author oversaw the third author's work as a stipended graduate student. While the three authors sought to develop shared ownership of the research process and decision-making, there was inherently a power imbalance between all three authors. This certainly played a role in how the research was conducted and how decisions were made, regardless of how much the second author, the university professor, worked to promote a democratic process in the research collaboration between all three authors. There were also unequal power differentials at play between the first author, who is a university staff member with a doctoral degree, and the second author, who became a tenured professor by the end of this study. These three different positions within the university, while unequal particularly as defined by compensation and social location, also offer a unique perspective and shared view into how the research developed as well as how the findings were reported.

\section{Participant Selection and Representation}

After developing a recruitment script approved by our IRB, the first author randomly selected community partners from our institutional database of organizations that had worked with our institution between 2016 and 2018. We were not interested in speaking with individuals from organizations to gain their insights about working specifically with our institution; rather, we sought their perspectives on service-learning more generally. After the initial outreach emails, the third author followed up with the individuals to confirm their participation. During the recruitment process, we explained to potential participants that our study would involve a 60-minute interview, which would take place on a date and location of their convenience. Our recruitment script also explained that the interview was part of our study to understand what ethical service-learning relationships looked like from the perspective of community partners. Table 1 provides anonymized information on the organizations at which the individuals worked.

Our institution's community engagement office works with service-learning courses across fields of study, serving graduate and undergraduate programs both on the ground and online. We thus work with partners across a large geographic area who are also often partnered with other local colleges and universities. While some of our service-learning courses involve direct service, many of our courses are project based, connecting students in professional preparation with nonprofit organizations to apply specific skills. To identify participants for the study we drew from a pool of all community organizations that had partnered with a service-learning course at our institution in the three academic years prior to the study. This resulted in a pool of 95 organizations that had partnered across 15 courses. Because of our specific context, this resulted in a range of organizations in terms of both size and service offered spread out across local communities. These partnerships were driven by both faculty, who sought partners for their course, and students, who for some courses found their own service-learning placements. Of these 95 partners we used a random number generator to identify 38 partners over three rounds. Of these 38 partners, 13 agreed to an interview (one didn't happen due to scheduling difficulties), 22 did not respond, and three responded that they were not interested. We sampled this way in order to reflect a variety of partners that represented our relationships at the university.

This method did have some drawbacks, however, and represents a limitation of the study. First, it's possible 
that larger, more well-staffed organizations were able to respond to our requests. We also ended up interviewing partner organizations that we did not necessarily have a close relationship with as an institution. Second, we are three researchers who identify as white working in a predominantly white institution (PWI) in a city with a large number of nonprofit organizations with predominantly white staff and leadership that often serve low-income communities of color. This study reflects those realities rather than challenges them. As practitioners interested in centering social justice within community practice, we see this research as a first step toward understanding community perspectives of service-learning ethics. Future researchers should consider over-sampling smaller organizations and those run by people of color to better represent these perspectives. In a similar vein, we reached out to and interviewed our initial points of contact at each organization rather than being attentive to the diverse voices that may have been available within those organizations to speak to our study. This allowed us to interview individuals we were sure had worked directly with service-learners. Nonetheless, future research should consider the diversity of individuals participating, rather than solely the organizations.

\section{Data Collection}

In an attempt to address some of the power dynamics in reaching out to those organizations that have worked with our institution, we consciously chose not to have the first author of this article, who works in the community engagement office at our institution, participate in the interviews with those in our study. Instead, the second author who was a tenure-track faculty member worked with the third author, a graduate student, to conduct the interviews both individually and as a team. In addition, the third author's experience, or perceived experience, shaped interview dynamics between subject and interviewer. At times the third author was mistaken as a professor by subjects, which potentially increased camaraderie and disclosure about service-learner behavior, while at other times the third author was treated as an intermediary between the subjects and faculty authors. Additionally, the third author found that drawing on experiences working with service-learners as a nonprofit employee also changed relational dynamics. In other words, the second and third authors experienced different conversational and relational dynamics depending on whether the interviews were conducted together or separately. In addition, where the interviews took place also impacted how people talked about the importance of relationships and what they assumed we knew about the ethical issues discussed.

\section{Analysis}

Because we were interested in understanding the perceptions of community partners related to the ethics of service-learning, we used "values coding” (Saldaña, 2016) to gain a deeper understanding of the values, attitudes, and beliefs of our participants regarding their experiences working with local colleges and universities. After transcribing the audio recordings of our interviews, we used the cloud-based software platform Dedoose (https://www.dedoose.com) for our qualitative analysis. During this first-level coding, we applied a “v:” for “values," an “a:" for attitudes, and a "b:” for beliefs in front of each of our codes in Dedoose. For example, "B: Service 
Table 1

Basic Demographic Information for the Organization Locations (as of May 2020)

\begin{tabular}{llll}
\hline Org. & Annual budget & Approx. staff size & Cause \\
\hline 1 & $500 \mathrm{k}-1$ million & 30 & Youth services \\
2 & $1-5$ million & 20 & Public libraries \\
3 & 990 unavailable & Org not found & Health and wellness \\
4 & $100 \mathrm{k}-500 \mathrm{k}$ & 20 & Safety education \\
5 & $1-5$ million & 20 & Public libraries \\
6 & $1-5$ million & 50 & Youth athletics \\
7 & 990 unavailable & unavailable & People with dementia \\
8 & 990 unavailable & unavailable & Youth services \\
9 & budget not found & 10 & Public libraries \\
10 & 10 million+ & 70 & Public libraries \\
11 & $500 \mathrm{k}-1$ million & 30 & Occupational safety/health \\
12 & 10 million+ & 120 & Homeless services \\
\hline
\end{tabular}

learning is impactful." This approach allowed our team to see how each of our codes corresponded with each of these three related categories.

After the first-level coding was completed in Dedoose, we grouped our codes by values, attitudes, and beliefs. To do this, the first-level codes were printed out onto sheets of paper. The third author then cut out the codes and created individual strips of paper for each code. These codes were then grouped together based on similar wordings. The third author worked to ensure that the groups were related, which resulted in many small groups. Some groups, such as "Background Check," did not change much since this initial grouping. Next, the third author took ungrouped codes and compared them to existing groups. If many similar words or concepts were expressed in a code, it was then added to the group. Anything that did not clearly fit into an existing group was placed into the "Miscellaneous" category until related codes were found.

Once all codes were placed in groups, the third author read through each group again and reorganized by putting similar concepts and wordings together. The third author named groups according to the concepts that held the groups together. Groups with overlapping concepts that were hard to differentiate were combined. This happened with "Service-Learner Skills" and "Dispositions" and a group called "Service Learner Motivation." Anything that seemed like an outlier was placed in "Miscellaneous," and the "Miscellaneous" category was revisited to see if any codes were similar to codes in existing groups. Anything that did not obviously align with codes in another group remained in "Miscellaneous."

The final list of codes during our second-level analysis resulted in the following: "Partnership," "Communication," "Partnership Process," "Guidelines and Expectations," "Preparation," "Service-Learning Project," "Service-Learner Skills and Dispositions," "Mutual Benefit," "Benefit to Org," "Benefits to Profession," "Benefits to Students," "Barriers," "Power Dynamics," "Time," "Constituents," "Other Harms," "Background Check," and "Miscellaneous." We also spent time writing sentences and phrases to describe each category, which we then discussed as a group.

For our third and final level of analysis, we focused on generating themes and statements from our secondlevel codes using Miro (https://miro.com). We drew lines from each of the codes and mapped the codes to 
Wendler's (2012) framework. For example, see Diagram 1. This process helped the three of us to make decisions together about how to group the codes. The authors met regularly during this process, using a deliberative analytical approach to determine how best to connect the second-level codes to the four ethical categories in Wendler's paper: respect, beneficence, justice, and reflexivity. The first two authors wrote extended memos about how the second-level codes connected with these four ethical areas, which all three of us discussed in the conclusion of our analysis.

\section{Limitations}

While our focus on gaining the perspectives of community partner organizations to help guide the development of ethical service-learning guidelines addresses a gap in the literature, we also understand that it only presents a partial view. In order to gain a more comprehensive picture of "community partner perspectives," that is, rather than only those of organizations, a much more robust methodological approach is needed to gain additional insights not only from constituents served by organizations but also from advisory board members of the organizations as well as other organizations and entities that partner with organizations. One way to address this limitation in our study would be to use a social ecological model (Kanauss, \& Shupe, 2014) with constituents at the center in the development of ethical service-learning guidelines. This approach would help to gain a more holistic understanding of the values, attitudes, and beliefs that shape not only the perspectives of community partner organizations regarding ethical service-learning but also how their constituents' insights could be centered as well. From there, additional perspectives of those who interact with both the individual constituent and the organizations could also be considered.

\section{Findings}

\section{Respect}

Drawing on decolonialist, feminist, and participatory research traditions, Wendler (2012) argues for the need to deepen the traditional research-based principle of respect as a defined autonomy recognized through a one-time acknowledgment of informed consent. Wendler recommended a "tweak" to this approach, suggesting that all stakeholders should be offered "a culturally responsive and revisable explanation of the project without coercion” (p. 31). Our interviews confirmed this approach to consent as a key issue from the community partner perspective. At the same time, the partners did not focus solely on consent; instead, the communication process more broadly emerged in our research as the central element of respect in the service-learning relationship. The community partner perspective on respect is broader than the narrow Belmont Report definition in that it is created over a much longer time period through multiple interactions. Two prongs of respect emerged from the partner perspectives: (a) respect for the partnership itself between the community organization and the univer- 


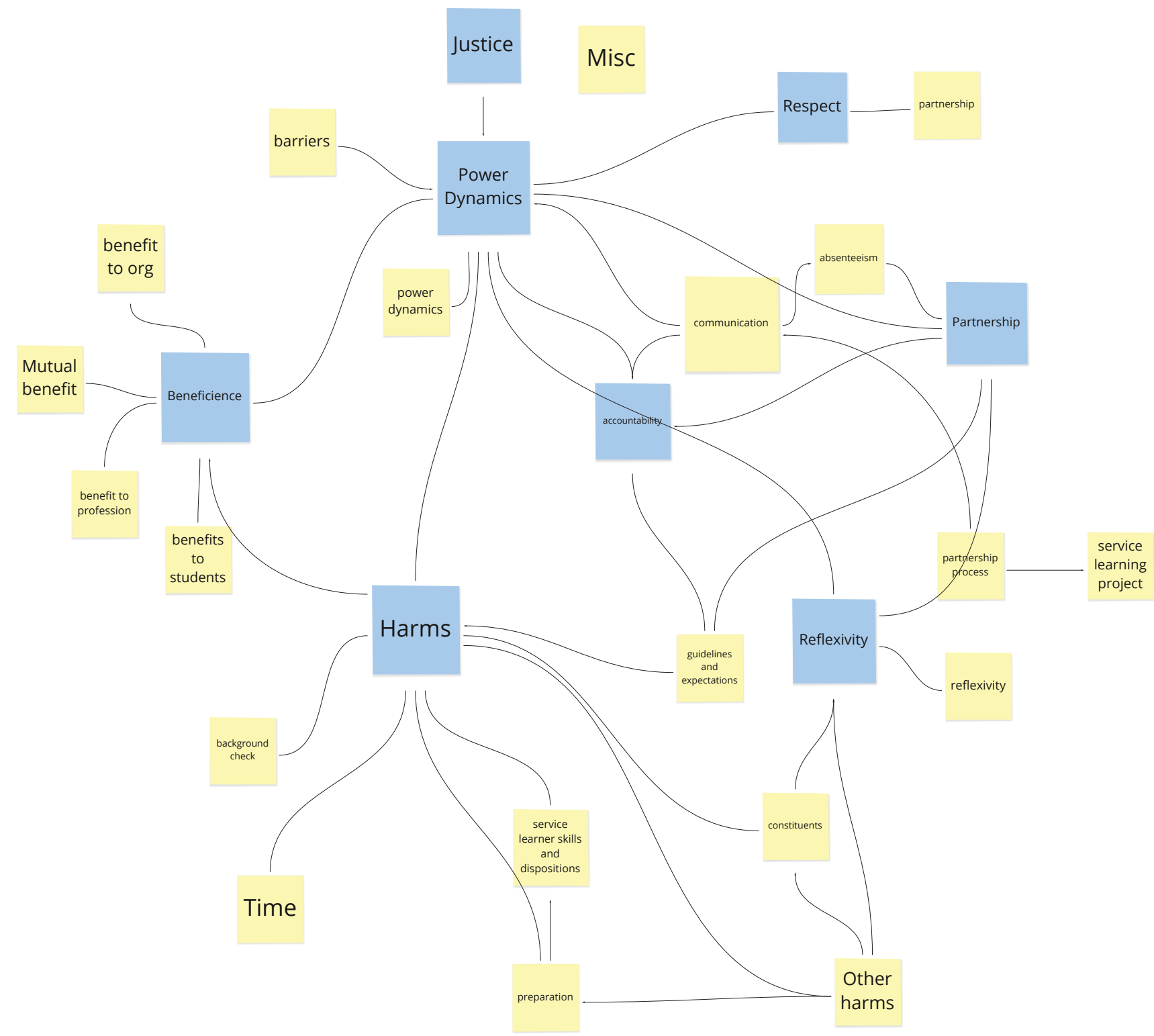

sity and (b) respect for persons within that partnership, particularly in the relationship between students and organization staff/constituents.

\section{Respect between Community-University Partners}

Since equity in a partnership must always be negotiated, communication is a critical mechanism for establishing and maintaining respectful service-learning partnerships. Strong communication enables mutual voice from the beginning of the process, when organizations must consider alignment of the project with their mission through the establishment of agreed-upon guidelines for students to final outcomes and post-project evaluation. While early preparation and good communication are clearly best practices, many partners suggested that a lack of 
clarity throughout service-learning projects is often a main barrier to success-making consent, as it is conceptualized from an ethical perspective, impossible. As one participant described:

Once you step into service-learning you're asking the [community partner] organization to provide learning in a way that the faculty member would. So we should be more aligned - the faculty member and whoever is the organization lead-so that if the students are doing whatever we're doing, we can draw them along feeling confident that we're together in where we're drawing them along to. And, I felt like I wasn't sure.

Some of our participants also raised the issue of consent in terms of which service-learners they worked with; several partners suggested they would prefer to interview or have some role in the selection of the people who came to their organizations - instead of just having individuals assigned to them. Early involvement with students and an element of choice provides the community partner more autonomy in the partnership.

Perhaps even more critical is the issue of undue influence. While none of our partners indicated that they felt directly coerced or pressured to participate, they did indicate external factors that influenced their consent. One partner we interviewed worried that one graduate student service-learner had connections to their board and therefore felt constrained in their work with that student. Other interviewees expressed concerns about troubling their relationships with their university partners through service-learning relationships.

I think maybe sometimes there's an element of we have to let students do certain things. Mostly what I was talking about before. Because if we don't then maybe next year we won't have any students. Kind of balancing that. I don't really want students running around and grabbing guests and taking pictures of them, but how does that weigh out with not having them here at all? I think sometimes we might allow things that we might not necessarily want to for fear of not having anybody next year.

Taken together, these findings reinforce the notion that consent is an ongoing issue in service-learning, one that needs to be addressed from an ethical perspective.

Respectful communication is key to the success of community-university partnerships in other ways as well. The participants in our study fleshed out multiple issues for consideration in a partnership focused on mutual voice and equitable participation, including the following: preferences for communication media (email, phone, text, etc.); style of communication (particularly expectations around professionalism and tact); substance of communication (expectations around giving progress reports and feedback); and volume of communication (how much, what to do about non-responsiveness). These important factors were raised several times, particularly with regard to the lack of sharing between university and community partners upon completion of projects. Each of these issues must be discussed to ensure that all partners are on the same page, can communicate openly and honestly, and have mutual voice in the process. 


\section{Respect within Community Organization-University Partnerships}

While respect for the partnership centers largely on the relationship between the faculty member/institutional staff and the community organization, respect for persons arose as an issue within the relationships between students and program staff/constituents as well. Program staff raised the level of student interest as a frequent issue when students are assigned to projects/sites.

I mean, the only thing that really comes to mind is if the person is really not engaged or not interactive or is there because the school says they have to fulfill that in-service-learning . . . if they're not engaged or they have an air about them that they don't want to be here then it doesn't do any advantages to us, it doesn't do any advantages to our kids, which is number one, and they're not going to get anything out of it. It's kind of a waste of everyone's time if that's the case.

When students make clear they are not interested in the work at hand, it threatens to derail the relationship and makes supervision significantly more challenging for partner organizations and potentially for the constituents they are working with. Finally, as we discuss in the next section, respect also surfaced as an issue between students and marginalized populations — where lack of respect might lead to potential harms.

\section{Beneficence}

In the research process, beneficence is generally unidirectional: there is some consideration to ensuring that research involving human subjects has some benefit to society, but largely the ethical concern is for maximizing benefits and minimizing harm to research subjects. As Wendler (2012) notes, the central ethical question in research is thus about ensuring the privacy and confidentiality of research subjects. She enumerates several harms to be considered in the service-learning context: emotional harms, human resource harms, service harms, program harms, and privacy and confidentiality harms. As in the research context, however, Wendler focuses largely on the latter by emphasizing privacy and confidentiality harms in her definition: "Potential harms are rigorously considered and minimized, including harms related to collecting and sharing community data” (p. 33). While privacy and confidentiality issues do surface in our research, we find that partners are equally concerned about other harms, particularly potential emotional harms and human resource harms. Furthermore, partners considered harms bidirectionally, indicating concern for mutuality and benefits for students as well as for their organizations and constituents.

The community partners we interviewed explained that when students work with marginalized and vulnerable populations, they need a positive attitude as well as training to learn how to work with those populations. Otherwise, a lack of understanding can lead to harm. Those organizations that had service-learners working directly with vulnerable populations, such as youth or people experiencing homelessness, asserted the need

to put their constituencies first and to protect them from harm from service-learners. These harms generally 
revolved around students' lack of experience and insensitivity with those populations. One partner raised the issue of privacy describing a case where a student took pictures of a homeless person as a part of their project with no regard for confidentiality:

One harm we sometimes see students treating people here as their projects. Like, it is my project to sit down with you and ask you, "Why are you homeless?" Which can sometimes, certainly cause emotional harm to the people we're serving. And you know, we try to say in the beginning, "Don't do x, y, z thing." But people, students try to take pictures, "This is the person I wrote my project about. Here's a picture of him.” NO! Because we have all kinds of privacy things here about not taking pictures of guests. First, just to make sure people are comfortable, but there can be some real harms that come to people just by people knowing where they are. People knowing they're here. So when I think of harms I really worry about our guests. Sometimes the impact that it's not necessarily the students' work here, but what they are bringing with them from assignments and things like that.

Another partner described the possibility for emotional harm that is particularly acute with youth and children, such as when a student belittled young people as a strategy for motivation.

Even when community partners expressed their concerns about harms to their constituents, they also stressed the need for mutual benefit in a strong service-learning partnership. While partners recognized that students are learning and can make mistakes, they were also interested in the role university partners could play in minimizing such harms, largely through better student preparation. At the same time, the participants in our study were still concerned with how they could work to ensure student learning in their partnerships with universities. As one partner explained, "I want not only our students who are part of our program to learn something from the college students coming in, but I also want our college students to learn something about the community that we work with.” From this perspective, service-learning works best when both the students and the young people served by the organization benefit from the experience.

Where students are not working with vulnerable populations, the concern for harm may not be as immediate, yet human resource and program harms remain quite real for partners. Working with students who, for whatever reason, don't produce the desired outcomes in a project can cause additional strain on organizational resources, particularly staff time. As one of our participants described:

There were a couple times when I felt like I was asked to do work that was clearly student work. And I was like, "I'm not doing that. That's your job.” Also just being respectful for my time. I'm extremely, extremely busy. . . . Frankly, I was surprised that he would come see the director of a large institution repeatedly sort of semi-prepared and incapable of communicating what he needed.

Nonetheless, some partners who didn't have direct constituents whom students were working with showed concern for student learning even to the detriment of their organization. As one community partner expressed, 
"I mean they do take up time. But that's part of the investment we make in the people who are going into this profession." They expressed a feeling of a sense of responsibility for training young people even when it took time and resources and they may not receive much in terms of outcomes in return.

\section{Justice}

Wendler (2012) explained that the principle of justice in ethical service-learning should pay careful attention to the micro-dynamics of community-university partnerships as well as to "macro-dynamics in society at large" (p. 37). This includes whether students are able to engage in issues of social justice in their service-learning and whether academic institutions have community partners focused on social justice goals. In response to our questions about the existence of power dynamics in their partnerships with academic institutions, community partners' answers included a wide range of responses. Many gave rich accounts of the micro-dynamics in their service-learning relationships, including between community partners and academic institutions and between community partners and students, as well as inter-organizational dynamics. Other organizations identified what we have labeled meso-dynamics - these are extra-organizational dynamics, such as between community partners and their boards of directors, local elected officials, and donors to organizations. Finally, our partners indicated a deep concern over the broader macro-dynamics of power in which both their organizations and universities are embedded.

\section{Micro-Dynamics}

In our interviews, partners expanded on the shared decision-making processes that Wendler (2012) centers as a principle of justice attendant to the micro-dynamics of power, including during the following activities: starting, designing, and ending relationships; choosing the students who work with their organizations; and building broad organizational relationships. As one partner explained:

There's already a power dynamic between the institution and nonprofit organization, so recognizing that and what that is and is it hierarchical and how we can collapse that, challenge that, or work with that. But also within organization and student, so the student is the representative of the institution and what do they take on then in terms of feeling empowered, entitled to a certain type of learning?

Partners explained that they often wished academic institutions shared the ability to make decisions about their service-learning partnerships in more equitable ways. This includes at the beginning of the partnership, as both groups begin to develop relationships and opportunities for the students' service-learning experiences. In fact, some partners mentioned that they appreciated even being informed at all about the project before it began. This is because as one partner, unfortunately, noted, "Some schools just have us on their list." Other participants in our study indicated that they did not feel forced to take on service-learners at their organizations, and others 
made it clear that they should have a choice not only to participate in service-learning but also to decide when to end their partnerships.

Community partners expressed their desire to have more ownership over decision-making processes, particularly regarding which students are allowed to work with their organizations as well as during the student evaluation process. Perhaps most concerning, partners expressed their reluctance to report negative issues involving students out of fear of damaging their relationship with the academic institution. Partners sometimes felt obligated to appease students because they were concerned about such repercussions, therefore allowing things they didn't want to happen. Because many community partners, particularly under-resourced organizations, frequently rely on students' service-learning contributions for capacity building and support, participants in our study mentioned their hesitancy to do anything that might put these relationships in jeopardy even when it came at the expense of the organization. This was particularly true when these relationships were valued by other stakeholders in the community.

Community partners described other micro-dynamic factors within their organizations. These included tensions between administrators and staff with regard to the nature of their relationships with academic institutions and the processes underlying their service-learning partnerships. One participant in our study talked about the importance of working within the organization to build good relationships with academic institutions, which can be helpful when having hard conversations about what's not working within the partnerships. This interorganizational communication can also be helpful, particularly at the beginning of a project, when making a determination about whether the partnership is a good fit. Having more support within the organization across administrators and staff can also help to create more support for decision-making with larger academic institutions.

\section{Meso-Dynamics}

The community partners we spoke with were not the only ones to value the role students play in service-learning partnerships. Some of our participants noted that their partnerships with local academic institutions were viewed in high regard by their board of trustees, local elected officials, and other stakeholders, including donors who give to their organizations. Therefore, this extra layer of power and influence, which we would add to Wendler's (2012) framework as a meso-dynamic level, includes extra-organizational actors that may cause ethical dilemmas in community partners' decision-making processes. For example, as one participant explained:

You know, donors are a big thing. They may give 100 thousand dollars to x, y, and z. They may sit on a board someplace. They may have a scholarship. You may be like, "You know I really don't want these kids, this is a lot of kids," but you make it work because it is a win-win. You put that extra effort in, you really should put that extra effort in because you need it. You need it. You need it, so you do it. That's just how it goes. Maybe when I'm the big boss I can make those kinds of decisions, but that's just kind of how it is. And you understand that and you make it work. That's it. 
Another participant mentioned that they loved telling their board about their partnerships with academic institutions in the area. Therefore, this meso-dynamic level includes actors just beyond the organization, in the community, that can play a more hidden, yet powerful role in influencing whether the community partners have a mutual voice in service-learning partnerships.

\section{Macro-Dynamics}

Wendler's (2012) discussion of macro-dynamics largely focuses on the role of faculty in distinguishing between justice and charity-orientation in how community organizations address social problems. Our community partners also expressed deep concern over macro-dynamics related to questions of justice in which universities and community organization relationships are embedded. These concerns suggest keen attention to questions of power related to the social, geographical, and economic privilege of all of the parties in the service-learning context—students, faculty, institutions, organizational staff, and organization constituents—regardless of how the organizations themselves address social problems.

Racial and economic segregation create real barriers for time- and cash-strapped students to regularly go where community organizations identify a need. The partners we interviewed were acutely aware of this issue as a limitation of working with university volunteers. Several noted there are some neighborhoods they have real trouble getting volunteers to and just not being able to work with university partners in these neighborhoods. The geographical divide is not only an issue of distance. As our participants noted, there is also prejudice against certain neighborhoods as well as taking the bus (rather than the subway) in general. These prejudices combine with structural transportation barriers to privilege certain neighborhoods and organizations in a competitive market for volunteer labor.

Reliance on volunteer labor was another structural issue that our partners raised. Several of our interviewees noted that their organizations are heavily reliant on volunteers and that students make up a large proportion of their volunteer labor. As one of our partners explained, "Free labor is always an ethical issue. But the thing that makes it different, I would hope, is that they're getting something out of it and that it's related to their course studies. If they can't really tie it back in a tangible way to their course related goals, then I question that." This was a problem for them on two fronts: some were concerned about relying on volunteer labor in the place of paid staff; others were concerned that their volunteers did not reflect the populations they served. As one of our participants described:

If we partner with universities that are predominantly white institutions, what does it say to our students if we're going in to teach them and our staff team is predominantly white and we're teaching a class of all students of color? I think that's a power dynamic that can be a little complicated. And I think sometimes just our staff team in general, whether its students or our staff, are not always adequately prepared to deal with or to acknowledge. I think that can be a little complicated. I don't know if I'm not ready to say that's necessarily harmful, but it is a little problematic. 
This social context of predominantly white universities and nonprofits working in communities of color is a serious social justice issue at least some participants in our study are aware of.

\section{Reflexivity}

The concept of reflexivity is not included in The Belmont Report and other more traditional approaches to research ethics. However, Wendler (2012) includes reflexivity as an ethical standard for service-learning, drawing on feminist approaches that emphasize situated knowledge and Indigenous objections to participating in research that only take a Western worldview into account. In our interviews, participants affirmed that student reflexivity is important to them and elaborated on the types of self-reflection they think students needed to effectively learn from their service-learning experiences with their organizations.

Several community partners commented on the importance of reflections particularly for students as they engage in service-learning projects. However, participants had different perspectives on how self-reflection can be incorporated into these learning environments as well as connected to deeper classroom discussions. For example, participants agreed that reflections provide students with opportunities to consider their own personal roles in service-learning projects, including reflecting on how their own experiences in high school might shape their engagements with youth in community settings. These personal reflections might also help students to "understand the importance of what they're doing" in service-learning projects, as another participant explained. Students can also use these opportunities as a vehicle for self-assessing their work on projects, including their interest level and ability to complete tasks.

Another community partner noted that reflection can also help students, particularly those wanting to make "change happen so fast." In this case, the community partner noted that ongoing reflection can help students both understand the longer-term process of social change while also appreciating the value of the everyday activities and experiences in service-learning projects. Community partners also noted the importance of sharing reflections with them or creating opportunities to reflect in community spaces. Because so many community partners take on the responsibility of teaching students, we learned, the participants in our study expressed that they would appreciate the opportunity to at least have access to student reflections, which can in turn better help students in their service-learning experiences.

Student reflection also provides opportunity for socio-emotional development, as one of the community partners explained. This process allows students to gain a deeper understanding of their own personal development. One respondent explained that the following questions can help support this process: How are you feeling when you hit high points or on a daily basis working on this project? Do you have regrets? What is stressing you out? What are those pressure points? In other words, reflexivity can be promoted for students not only to realize the value of their service-learning work with communities but also in grappling with and better understanding some of the feelings they might experience in new community settings.

Only in one example did a community partner make a more direct connection to issues of power in the ways that Wendler (2012) conceptualized, particularly in the following questions asked: How does your background 
Table 2

Comparison Between Wendler Definition and Community Partner Perspectives

\begin{tabular}{ll}
\hline Ethical principle & Wendler (2012) definition \\
\hline Respect for persons & $\begin{array}{l}\text { Stakeholders are offered a culturally responsive } \\
\text { and revisable explanation of the project, without } \\
\text { coercion. Consent is continually renegotiated-in } \\
\text { relationships. Respectful, asset-based frameworks } \\
\text { guide interactions and representations. }\end{array}$
\end{tabular}

Beneficence

Justice

Reflexivity

Projects benefit both the university and community. Potential harms are rigorously considered and minimized, including potential harms related to collecting and sharing community data.
Community partner perspective

Respectful communication is key to the success of community-university partnerships based on consent, particularly related to the preferences, style, substance, and volume of communication between partners.

$\rightarrow$ partners understanding the learning objectives and playing part in the teaching.

Respectful community-university partnerships must include support for community partners to be able to express their concerns about student-learners without negative repercussions from universities.

Beneficence in community-university partnerships requires that students have a positive attitude and receive training needed to work with marginalized populations. Otherwise, a lack of preparedness and understanding can lead to harm.

Attention to human resource and program harms in addition to privacy and confidentiality

Justice in community-university partnerships includes:

- the ability of community partners to have more ownership over decision-making processes in service-learning projects;

- the importance of strong relationships to support the ability to have difficult conversations when things are not working well;

- being able to address the meso-dynamic factors that include actors that can play a hidden, yet powerful role in influencing whether community partners have a mutual voice in service-learning partnerships;

- power to respond to prejudice against students working in racially and economically segregated communities, combined with structural transportation barriers that privilege certain neighborhoods and organizations in a competitive market for volunteer labor, creating unjust foundations for ethical service-learning; and

- responding to concerns among community partners related to university reliance on free volunteer labor from students.

Reflexivity in community-university partners includes student reflection focused on the following: how who one is shapes one's perceptions of the service-learning situation, including recognition that one's viewpoint is not absolute.
- students' personal roles in service-learning projects, including reflecting on how their past experiences shape their current and future engagements with constituents in community settings;

- the longer-term process of social change while also appreciating the value of the everyday activities and experiences in service-learning projects;

- opportunities for socio-emotional development to help students gain a deeper understanding of their own personal development before, during, and after service-learning projects; and

- how students' personal identities shape the power they have within service-learning experiences. 
impact your perception of the partnership's ethical dynamics? How will you solicit a variety of perspectives on ethical issues? How will you teach students to consider their positionality when interpreting service-learning experiences? In this case, the community partner clearly stated that students should reflect on how their identities shape the power they have within service-learning experiences. In terms of teaching students to consider their positionality, the community partner suggested the following for instructors of service-learning projects: "I think in an academic environment with other students or with the support of their professor is a great place to be thinking about some of that." The same community partner stated that there are times when there is a "cultural clash" or a "difference in cultural values" between the students from the university and the constituents served by the community partner. This statement supports the need for deeper reflection on the social location of students, activities that can be important for the instructor to lead as a way to help reduce harms in community settings.

\section{Discussion}

As practitioners of critical service-learning, we endeavor to center social justice in our work in the classroom and with community, as previous studies have emphasized (Mitchell, 2008). In order to center social justice, we have found we need an "ethics of interaction" (Padmanabha, 2018, p. 146), which ground us in a critical, justiceoriented approach. Wendler (2012) offers a framework that builds on work in research ethics without replicating those structures and is informed by feminist and Indigenous methodologies. Wendler's framework, nonetheless, comes from within the academy. The findings in our study have helped to show how a community partner perspective of this framework might inform our practice further.

The community partner perspective on ethical service-learning in our study further reinforced the need for an ethical foundation for the work of building partnerships. As Padmanabha (2018) found in transforming service into learning with students, best practices aren't enough to ensure a solid ethical relationship between university and community partners. Wendler (2012) offers us a framework of four separate if overlapping categories for a service-learning ethics: respect, beneficence, reflexivity, and justice. Yet issues of justice are central to the three remaining categories. When we center justice in our analysis, we hear a call for a relational ethics from our partners. What emerges then is an understanding of the pursuit of just partnerships as a both a process requiring respect and reflexivity as well as a mutually beneficial outcome. While outcomes were of concern to our community partners and the need for mutually beneficial outcomes in service-learning are well documented in the literature (Clayton et al., 2010; Sandy \& Holland, 2006; Stoecker \& Tryon, 2009), the aspects of the process-both in terms of reflexivity and respect—stand out most clearly in our interviews.

The findings in our study, grounded in the ethical perspectives of our community partners, help to further emphasize the importance of what we are calling a relational approach to service-learning ethics. In practice, this means centering the goal of just relationships (rather than the service or the learning) as the starting point for ethical service-learning. Our findings build on previous studies that have shown the importance of relationships from the perspective of community partners (Clayton et al., 2010; Glover \& Silka, 2013; Goldberg \& Atkins, 
2020; Sandy \& Holland, 2006; Shore, 2006; Stoecker \& Tryon, 2009; Tinkler et al., 2014). However, we believe that the findings in our study, which help to show how community partners perceive and articulate ethical service-learning, contribute additional insights to promote future research and practice grounded in this relational approach to service-learning ethics.

This relational approach to ethical service-learning centers social justice in community-university partnerships by focusing on the following relational needs:

1. explicitly recognizing power dynamics in faculty, student, and organizational partnerships throughout the engagement process;

2. open communication and consent that supports freedom of expression among community partners without repercussion from institutions;

3. co-designing the service-learning terms and conditions in ways that promote equity among partners;

4. shared ownership of both the process and outcomes of ethical service-learning;

5. careful attention to human resource and program harms, including but not limited to issues of privacy and confidentiality among constituents;

6. questioning the role of academic institutions in reinforcing a reliance on unpaid student labor among community partner organizations; and

7. creating additional opportunities in community settings to foster and support student reflexivity.

We believe these seven needs offer additional key areas that both build upon and extend Wendler's (2012) framework as well as Padmanabha's (2018) ethics of interaction, with a focus on socially just relationships in community-university partnerships. It is important to recognize, as our partners do, that these relationships are often occurring in an unjust context of not only community-university relationships but also the relationships of marginalized communities to the broader society. This includes power differentials and long histories of oppression and exploitation. This forms a basis for our reflexivity-of the macro-, meso-, and micro-dynamics of power at play in our relationships and for how we communicate with our partners, which is a central element of demonstrating respect from the partner perspective. Shifting from a "best practices" frame to an ethics frame, in terms of both respect and reflexivity, creates a space for faculty training and for institutions to consider how we might be more deliberate in our approach to both reflexivity and respect.

\section{Implications for Our Practice}

While our institution is predominantly white, our community partners serve a much more diverse group of constituents. At the same time, several of our community partner organizations are also predominantly white. In addition, the three of us, as both the authors and former practitioners in community-based organizations, are white. We all share a relatively similar perspective of the work that our partners do as well as a concern about our own limitations in understanding the experiences of the constituents served by our community partner orga- 
nizations. In this study, we found that participants reflected on how their institutions could do better in terms of representing the communities they serve. We also recognize that the voices of those interviewed in our study most likely don't reflect the full range of experiences of community-based organizations in our region, including the types and quality of relationships they have with both their students and communities. This reality is also reflected in the list of organizations included in Table 1.

We want to fully acknowledge that the research presented in this article reflects our own positionality as well as the interpretation of service-learning ethics from our community partners. We offer these perspectives as part of a larger conversation that we hope to bring into focus as we continue to develop our own practice and scholarship of engagement. The seven principles presented above will inform how we conduct community-engaged teaching and develop policies and proposals for our faculty and students. While we were unable to perform member checking, that is, allowing our research participants to verify the findings of our study, seven principles are rooted in the perspectives of our community partners. As such, we take their contributions seriously and plan to use them to guide our work moving forward as both practitioners and educators. This includes increased ownership of any research processes included in service-learning partnerships inside and outside the classroom in the future.

It is also important to point out that the constituents of the community-based organizations we interviewed are absent in this study. This is because we sought the perspectives of those who work in community-based organizations with institutions of higher education in our area. The constituent perspective is an important component that would benefit from future community-engaged research to better highlight their voices and concerns from an ethical point of view. A few of the community partners that participated in this study did mention that they didn't want to harm their relationships between their organizations and academic institutions, therefore we believe there is more to address in terms of the power inequities in this research. We believe these relational dynamics contributed to the findings of this article as well as the overall discussion about relationships in the ethics of community service-learning.

\section{Conclusion}

In this article, we presented findings from a study of community partner perspectives on ethical service-learning. We used Wendler's (2012) ethical service-learning framework, which is grounded in decolonial, feminist, and participatory approaches, to understand how community partners interpreted issues related to respect for persons, beneficence, justice, and reflexivity in service-learning partnerships. We found that Wendler's framework was useful in uncovering issues of power and inequality in community-university partnerships as well as in helping us to understand what a more just vision for service-learning that's rooted in the concerns and aspirations of our community partners looks like. Our findings showed that community partners expressed their desire to have more ownership over decision-making processes and that strong relationships grounded in open communication and consent were critical to the success of service-learning projects. We introduced the concept of a relational approach to service-learning ethics, which builds upon existing studies showing the importance of relationships 
and participatory approaches in community service-learning. However, our contribution to the literature offers researchers and practitioners with an additional seven key anchors to ground the ethics of service-learning in social justice from the perspective of community partners. We believe this relational approach can help to ensure more just and equitable processes and outcomes in community-university partnerships.

Relationships are especially critical right now given the impacts of the COVID-19 pandemic. Institutions of higher education in the United States are being forced to rethink what they do and as a result are making their own decisions about how to survive. In the meantime, those of us in community engagement positions within academia continue to focus on the relationships we have with our community partners. These relationships are perhaps more important now than ever, particularly as events beyond the pandemic, including those caused by systemic racism and police brutality, continue to devastate the communities within which we live and work. As engaged scholars and practitioners, we can't change the large-scale decisions being made in executive positions within our institutions. We also can't make unilateral decisions from an engagement perspective. However, we need tocan listen to the expectations of our community partners during these current crises and into the future. We believe this time presents an opportunity for solidarity while recognizing that harms are not distributed equally.

\section{Author Note}

We have no known conflict of interest to disclose.

Correspondence concerning this article should be addressed to Meghan Doran, email: meghan.doran2@simmons.edu.

\section{References}

Blizek, W. L. (2013). Service learning: The odd case of ethics. Teaching Ethics, 13(2), 73-84.

Bringle, R. G., Clayton, P. H., \& Price, M. (2009). Partnerships in service learning and civic engagement. Partnerships: A Journal of Service Learning and Civic Engagement, 1(1), 1-20.

Bringle, R. G., \& Hatcher, J. A. (2002). Campus-community partnerships: The terms of engagement. Journal of Social Issues, 58(3), 503-516.

Bucher, J. (2012). Old and young dogs teaching each other tricks: The importance of developing agency for community partners in community learning. Teaching Sociology, 4O(3), 271-283.

Chapdelaine, A., Ruiz, A., Warchal, J., \& Wells, C. (2005). Service-learning code of ethics. Anker Publishing.

Clayton, P. H., Bringle, R. G., Senor, B., Huq, J., \& Morrison, M. (2010). Differentiating and assessing relationships in service-learning and civic engagement: Exploitative, transactional, or transformational. Michigan Journal of Community Service Learning, 16(2), 5-21.

Danley, S., \& Christiansen, G. (2019). Conflicting responsibilities: The multi-dimensional ethics of university/ community partnerships. Journal of Community Engagement E'Scholarship, 11(2), 8-18. 
Garoutte, L. (2018). The sociological imagination and community-based learning: Using an asset-based approach. Teaching Sociology, 46(2), 148-159.

Glover, R. W., \& Silka, L. (2013). Choice, power and perspective: The neglected question of who initiates engaged campus-community partnerships. Gateways: International Journal of Community Research $\sigma^{\circ}$ Engagement, $6(1), 38-56$.

Goldberg, N., \& Atkins, L. C. (2020). Community partners as service-learning co-leaders. Collaborations: $A$ Journal of Community-Based Research and Practice, 3(1), 2.

Gorski, I., Obeysekare, E., Yarnal, C., \& Mehta, K. (2015). Responsible engagement: Building a culture of concern. Journal of Community Engagement and Scholarship, 8(2), 16-25.

Holmes, A. J. (2009). Advancing campus-community partnerships: Standpoint theory and course re-design. Reflections, 8(3), 76-98.

Kanauss, L., \& Shupe, E. (2014). Nutrition-related service learning activities on a university campus. International Journal of Health, Wellness E' Society, 4(2), 29-37.

Mikesell, L., Bromley, E., \& Khodyakov, D. (2013). Ethical community-engaged research: A literature review. American Journal of Public Health, 103(12), e7-e14.

Mitchell, T. D. (2008). Traditional vs. critical service-learning: Engaging the literature to differentiate two models. Michigan Journal of Community Service Learning, 14(2), 50-65.

National Commission for the Protection of Human Subjects of Biomedical and Behavioral Research. (1979). The Belmont report: Ethical principles and guidelines for the protection of buman subjects of research. https:// www.hhs.gov/ohrp/sites/default/files/the-belmont-report-508c_FINAL.pdf.

O’Brien, K., Wittmer, D., \& Ebrahimi, B. P. (2017). Behavioral ethics in practice: Integrating service learning into a graduate business ethics course. Journal of Management Education, 41(4), 599-616.

Padmanabha, S. (2018). Indigenous methods and pedagogy: Revisiting ethics in community service-learning. Engaged Scholar Journal, 4(1), 143-160.

Paul, H. (2018). The scientific self: Reclaiming its place in the history of research ethics. Science and Engineering Ethics, 24(5), 1379-1392.

Racin, L., \& Gordon, E. (2018). Community academic research partnerships in digital contexts: Opportunities, limitations, and new ways to promote mutual benefit. https://elabhome.blob.core.windows.net/resources/ mou.pdf.

Reed, P., \& Butler, T. (2015). Flipping the script: When service-learning recipients become service-learning givers. Theory Into Practice, 54(1), 55-62.

Reisch, M., Ife, J., \& Weil, M. (2012). Social justice, human rights, values, and community practice. In M. Weil, M. Reisch, \& M. L. Ohmer (Eds.), The handbook of community practice (2nd ed., pp. 73-103). Sage Publications.

Rich, B. (2003). Ethical issues and questions for service-learning faculty and administrators in urban universities. Metropolitan Universities, 14(3), 111-121.

Saldaña, J. (2016). The coding manual for qualitative researchers (3rd ed.). Sage Publications. 
Sandy, M., \& Holland, B. A. (2006). Different worlds and common ground: Community partner perspectives on campus-community partnerships. Michigan Journal of Community Service Learning, 13(1), 30-43.

Shore, N. (2006). Re-conceptualizing the Belmont Report: A community-based participatory research perspective. Journal of Community Practice, 14(4), 5-26.

Stoecker, R., \& Tryon, E. A. (Eds.). (2009). The unheard voices: Community organizations and service learning. Temple University Press.

Tinkler, A., Tinkler, B., Hausman, E., \& Strouse, G. T. (2014). Key elements of effective service-learning partnerships from the perspective of community partners. Partnerships: A Journal of Service-Learning $\sigma^{2}$ Civic Engagement, 5(2), 137-152.

Wendler, R. (2012). Human subjects protection: A source for ethical service-learning practice. Michigan Journal of Community Service Learning, 18(2), 29-39.

Worrall, L. (2007). Asking the community: A case study of community partner perspectives. Michigan Journal of Community Service Learning, 14(1), 5-17.

\section{Authors}

MEGHAN DORAN is the Assistant Director for Service-Learning at Simmons University. In this role she supports faculty development around best practices in community-based learning and works to build mutually beneficial partnerships that enhance student learning while addressing community needs and interests. She holds a PhD in Sociology and teaches courses on social justice and youth leadership.

COLIN RHINESMITH is an Associate Professor and Director of the Community Informatics Lab in the Simmons University School of Library and Information Science. He is also the Editor-in-Chief of The Journal of Community Informatics. Rhinesmith received his $\mathrm{PhD}$ in Library and Information Science from the University of Illinois at Urbana-Champaign.

SARAH ARENA is the Data Manager for the Harvard Program in Therapeutic Science at Harvard Medical School. She is a two-year AmeriCorps/AmeriCorps VISTA alumna and has worked both as a service-learning student and as a community partner overseeing service-learners. She holds a BA in History from Grinnell College and an MS in Library and Information Science from Simmons University. 